\title{
Associações genotípicas entre componentes de produção e caracteres agronômicos em feijão-caupi ${ }^{1}$
}

\author{
Genotypic associations between production components and agronomic \\ characteristics in the cowpea
}

\author{
Odiluza Maria Saldanha de Oliveira² ${ }^{2}$ José Ferreira da Silva ${ }^{3 *}$, Fábio Medeiros Ferreira ${ }^{4}$, Cristiane da Silva \\ Klehm² e Catiele Vieira Borges $^{2}$
}

\begin{abstract}
RESUMO - A análise de coeficiente de correlação é uma importante ferramenta no estudo da associação entre os caracteres de feijão-caupi e para avaliar a contribuição de cada fator na produtividade desta cultura. Objetivou-se investigar as relações genotípicas entre a produtividade de grãos em feijão-caupi e alguns componentes de produção e características agronômicas, utilizando a análise de trilha para decompor as correlações em seus efeitos diretos e indiretos. O experimento foi realizado no período de maio a agosto de 2010. Foram utilizadas as cultivares BR8 Caldeirão, IPEAN V69, BRS Guariba e BR17 Gurguéia. Estimou-se as correlações genotípicas entre pares de caracteres e seus efeitos diretos e indiretos considerando os componentes de produção (número de vagens.planta ${ }^{-1}$ e número de sementes.vagem ${ }^{-1}$ ), caracteres agronômicos (altura da planta, área foliar e peso da matéria seca da parte aérea) e a produtividade de grãos. O diagrama de trilha com duas cadeias mostrou-se adequado em explicar as relações entre componentes primários, secundários e produtividade, considerando as altas estimativas dos coeficientes de determinação $\left(\mathrm{R}^{2}\right)$ e baixos efeitos residuais. O número de vagens.planta ${ }^{-1}$ e a área foliar foram os caracteres mais correlacionados com a produtividade e se mostram eficientes em praticar-se seleção indireta, com o intuito de obter ganhos genéticos sobre o rendimento de grãos. Também mostraram ser caracteres importantes sobre os efeitos indiretos do número de sementes vagem ${ }^{-1}$, altura da planta e peso da matéria seca da parte aérea.
\end{abstract}

Palavras-chave: Feijão-caupi. Interação genótipo-ambiente.

\begin{abstract}
Analysis of correlation coefficients is an important tool, not only in the study of the association between the characteristics of the cowpea but also in evaluating the contribution of each factor to the productivity of the crop. The objective was to investigate the genotypic relationships between grain productivity in the cowpea and various production components and agronomical characteristics, by using path analysis to break down such correlations in both their direct and indirect effects. The experiment was carried out from May to August of 2010. The cultivars used were BR8 Cauldron, IPEAN V69, BRS Guariba and BR17 Gurguéia. Genotypical correlations between pairs of characteristics, together with their direct and indirect effects were estimated, taking into consideration production components (number of pods per plant and number of seeds per pod), agronomic features (plant height, leaf-area and shoot dry-matter weight) and grain productivity. A path diagram containing two path-chains was sufficient to explain the relationships between the primary and secondary components and productivity when the high estimates of the coefficients of determination $\left(\mathrm{R}^{2}\right)$ and the low residual effects were considered. The number of pods per plant, and leaf-area were those characteristics which most correlated with productivity, and would appear to be efficient for indirect selection, where the intention is to obtain genetic gains in grain yield. They were also seen to be important characteristics for the indirect effects of the number of seeds per pod, plant height and shoot dry-matter weight.
\end{abstract}

Key words: Cowpea. Genotype-environment interaction.

\footnotetext{
*Autor para correspondência

${ }^{1}$ Recebido para publicação em 09/05/2012; aprovado em 09/03/2013

Parte da Tese de Doutorado apresentada ao Programa de Pós-Graduação em Agronomia Tropical da Universidade Federal do Amazonas

${ }^{2}$ Departamento de Programa de Pós-Graduação em Agronomia Tropical da Universidade Federal do Amazonas/UFAM, Manaus-AM, Brasil, odiluza@hotmail.com, cristianeklehm@hotmail.com, catieleborges@hotmail.com

${ }^{3}$ Departamento de Produção Animal e Vegetal, Universidade Federal do Amazonas/UFAM, Manaus-AM, Brasil, jfsilva@ufam.edu.br

${ }^{4}$ Instituto de Ciências Exatas e Tecnologias, Universidade Federal do Amazonas/UFAM, Itacoatiara-AM, Brasil, fmferreira77@gmail.com
} 


\section{INTRODUÇÃO}

O feijão-caupi se constitui em uma das principais alternativas sociais e econômicas para as populações rurais nas regiões Norte e Nordeste do Brasil (OLIVEIRA et al., 2010). Atualmente, há a expansão do cultivo desta leguminosa para a região centro-oeste para fins de exportação (ROCHA et al., 2009). A demanda por cultivares adaptadas aos sistemas produtivos exige dos programas de melhoramento maior enfoque no aumento da produtividade, qualidade de grãos e arquitetura de planta (FREIRE FILHO et al., 2007).

Para a obtenção do material genético desejado é importante que se conheça as relações genéticas existentes entre características de interesse agronômico (ANDRADE et al., 2010), que podem se associar em direções e magnitudes distintas (SILVA; NEVES, 2011). Conhecer tais relações possibilita que uma variável principal, caracterizada por baixa herdabilidade ou dificuldade de medição, tenha a seleção com base em outra (FERREIRA et al., 2007).

Dentre os métodos empregados para se compreender o grau e tipos de associações entre vários caracteres conjuntamente está à análise de trilha. Este método baseia-se na definição prévia do caráter principal e de outras explicativas cujas inter-relações lineares são decompostas em componentes de efeitos diretos e indiretos, considerando um modelo aditivo de regressão linear múltipla (CABRAL et al., 2011).

O diagrama de trilha em feijão-caupi tem sido estabelecido com apenas uma cadeia de associação causaefeito envolvendo os mais variados caracteres (BEZERRA et al. 2001; SOUZA, 2005). Poucos são os estudos que envolvem diagramas de trilha com duas cadeias em espécies de feijão (COIMBRA et al., 1999), provavelmente em razão da maior complexidade da análise, interpretação e diagnóstico de multicolinearidade.

A produtividade de grãos em feijão é um caráter complexo, resultante dos efeitos multiplicativos dos seus componentes primários cuja herdabilidade no sentido amplo é moderada a baixa (RAMALHO; SANTOS; ZIMMERMANN, 1993). Caracteres quantitativos estão sob controle de vários genes susceptíveis às interações genótipo $\mathrm{x}$ ambiente, desequilíbrio de ligação e efeitos pleiotrópicos (ZILIO et al., 2011). Componentes primários de produção são tidos como complexos, de baixa herdabilidade, portanto, difíceis de serem selecionados, sendo necessário definir a relação dos caracteres morfoagronômicos sobre os componentes primários e sobre a produtividade (KRAUSE; RODRIGUES; LEAL, 2012).

O objetivo do experimento foi definir as relações genotípicas entre a produtividade de grãos e características agronômicas em feijão-caupi.

\section{MATERIAL E MÉTODOS}

$\mathrm{O}$ experimento foi realizado no período de maio a agosto de 2010 na Fazenda Experimental da Universidade Federal do Amazonas, no município de Manaus, Amazonas - Brasil. As coordenadas geográficas locais de referência são $02^{\circ} 39^{\prime} \mathrm{S}$ e $60^{\circ} 03^{\prime} \mathrm{W}$ e altitude de $12 \mathrm{~m}$. O clima da região, segundo a classificação de Köppen, é Af com temperatura média anual de $27^{\circ} \mathrm{C}$, pluviosidade média anual de $2.362 \mathrm{~mm}$ e umidade relativa do ar em torno de 75\% (VIANELLO; ALVES, 2002).

$\mathrm{O}$ solo da área do experimento foi classificado como Latossolo Amarelo Álico. O preparo do solo foi feito no sistema convencional, com uma aração seguida de duas gradagens. A correção da acidez do solo e a adubação foram realizadas atendendo às recomendações para a cultura (FREIRE FILHO et al., 2005). Foram utilizados 1,5 t/ha de calcário dolomítico (PRNT 90\%) na calagem e $60 \mathrm{~kg} \mathrm{ha}^{-1} \mathrm{P}_{2} \mathrm{O}_{5}$ e $30 \mathrm{~kg} \mathrm{ha}^{-1} \mathrm{~K}_{2} \mathrm{O}$ na adubação de plantio. A semeadura das cultivares foi manual. A irrigação foi realizada por aspersão, de modo a garantir o suprimento hídrico, que variou de 3,00 a 7,00 mm de água por dia conforme o estádio de desenvolvimento da planta.

O delineamento experimental foi de blocos casualizados, com três repetições, em parcelas sub-subdivididas. $\mathrm{Na}$ parcela, foram usados os espaçamentos de 0,50; 0,40 e 0,30 m entrelinhas; nas subparcelas as cultivares IPEAN V69, BR8 Caldeirão; BRS Guariba; BR17 Gurguéia e nas sub-subparcelas dois sistemas de manejo de plantas daninhas, com e sem capina. Cada unidade experimental tinha $48 \mathrm{~m}^{2} \mathrm{de}$ área total e número variável de linhas, de acordo com o espaçamento. As subparcelas apresentaram área total de $12 \mathrm{~m}^{2} \mathrm{e}$ as sub-subparcelas de $6 \mathrm{~m}^{2}$ com área útil da sub-subparcela de $2 \mathrm{~m}^{2}$. A densidade populacional de feijão-caupi foi de 200.000 plantas por hectare (controle) quando utilizado espaçamento entrelinhas de $0,5 \mathrm{~m}$. Em espaçamentos de 0,4 e $0,3 \mathrm{~m}$ o estande foi de 250.000 e 333.330 plantas, respectivamente.

Os critérios para escolha das cultivares foram apresentar ciclo precoce; porte ereto, semiereto ou prostrado e grãos com coloração bem aceitas pelos consumidores. Todas as cultivares apresentam hábito de crescimento indeterminado e ciclo precoce.

Os caracteres avaliados foram altura da planta (AP), medida da superfície do solo até a inserção da última vagem, em 10 plantas ao acaso, por ocasião da primeira colheita; área foliar (AF) média das áreas das lâminas foliares das plantas coletadas, inferida com determinador de área foliar; peso da matéria seca da parte aérea (PMSPA) soma da massa seca das folhas (MSF) e da massa seca do caule (MSC); número de 
vagens planta $^{-1}$ (NVP), obtido dividindo-se o número total de vagens pelo número de plantas na área útil de cada sub-subparcela, contadas na colheita; número de sementes vagem ${ }^{-1}$ (NSVG), obtido dividindo-se o número total de sementes pelo número de vagens de cada sub-subparcela, e produtividade de grãos (PROD), após a colheita realizada quando $90 \%$ ou mais das vagens estavam maduras e em seguida foram secadas em estufa e a umidade dos grãos obtidos corrigida para 13\%. Os grãos foram pesados e estes valores transformados em produtividade $\left(\mathrm{kg} \mathrm{ha}^{-1}\right)$. Para as avaliações da área foliar e peso da matéria seca da parte aérea, foram coletadas cinco plantas de feijão-caupi por sub-subparcela, fora da área destinada à produtividade, amostradas em intervalos de 7 dias até o fim do experimento. A colheita foi realizada 70 dias após a semeadura.

Como a relação entre número de vagens planta ${ }^{-1}$ e o número de sementes vagem ${ }^{-1}$ com a produtividade é estruturalmente multiplicativa, os valores observados destes três caracteres foram transformados para escala logarítmica, mantendo-se um modelo aditivo para se realizar a análise de trilha. As correlações genotípicas entre os pares de caracteres foram obtidos por meio dos componentes de covariância estimados pela esperança dos produtos médios das fontes de variação do modelo estatístico (CRUZ; REGAZZI; CARNEIRO, 2004). As correlações genotípicas tiveram suas significâncias verificadas pelo teste de Mantel, com 5.000 simulações, a $5 \%$ de significância.

Considerou-se duas cadeias para a realização do diagrama causal na decomposição das relações genéticas entre a produtividade e os componentes primários e secundários sob diferentes efeitos diretos e indiretos. Antes de realizar a análise, diagnosticouse colinearidade fraca na matriz $X^{\prime} X$, composta pelos caracteres explicativos, com base no critério de Montgomery e Peck (1981). As análises genéticas foram realizadas com auxílio do software GENES versão 2009.7.0 (CRUZ, 2006).

\section{RESULTADOS E DISCUSSÃO}

Antes da decomposição das relações de causa e efeito entre os componentes de produção, avaliou-se o grau de multicolinearidade da matriz de correlações padronizadas entre os caracteres avaliados. Apenas duas correlações genotípicas foram significativas (Tabela 1).

Como no presente estudo avaliaram-se quatro cultivares, provavelmente a construção das distribuições empíricas para verificar a significância pelo teste de Mantel foi afetada pelo número de cultivares. Em estudos futuros sobre estimação da correlação genotípica sugere-se maior número de cultivares. Contudo, existiram estimativas de correlação genotípica ( $\mathrm{r}$ ) elevadas e positivas, como o número de vagens planta ${ }^{-1}$ (NVP) e produtividade (PROD) $\left(\mathrm{r}_{\mathrm{NVPXPROD}}=0,977\right)$; peso da matéria seca da parte aérea (PMSPA) e PROD $\left(\mathrm{r}_{\mathrm{NVPXPROD}}=0,907\right)$; número de sementes vagem $^{-1}$ (NSVG) e PMSPA $\left(\mathrm{r}_{\text {NSVGxPMSPA }}=\right.$ 0,942); NVG e PMSPA $\left(\mathrm{r}_{\text {NVPXPMSPA }}=0,828\right)$ e; área foliar (AF) e PMSPA $\left(\mathrm{r}_{\mathrm{AFxPMSPA}}=0,702\right)$. Correlações positivas e altamente significativas foram consideradas entre AFxNVP e AFxPROD. Entretanto, é preciso observar que para um valor prático de seleção as variáveis também estejam correlacionadas fenotipicamente (FERREIRA et al., 2007). Caracteres que apresentam alto componente genético em suas expressões fenotípicas levam à obtenção de ganhos via seleção visual (ANDRADE et al., 2010).

A altura das plantas correlacionou-se negativamentecomPMSPAeNSVG(Tabela 1). Cultivares de hábito de crescimento indeterminado apresentam sobreposição das fases vegetativa e reprodutiva, o que interfere na relação fonte:dreno e resulta em consequente mudança na distribuição dos fotoassimilados nas plantas adultas com alterações na morfologia, nos componentes de produção e no rendimento de grãos (BEZERRA et al., 2009). Resultado divergente foi constatado por Cabral et al. (2011) que ao analisarem a relação da altura da planta com os componentes primários de produção verificaram sentido positivo e magnitude significativa.

Tabela 1 - Matriz das estimativas de correlação genotípica ${ }^{\#}$ entre número de vagens.planta ${ }^{-1}$ (NVP), número de sementes.vagem ${ }^{-1}$ (NSVG), produtividade (PROD), altura da planta (AP), área foliar (AF) e peso da matéria seca da parte aérea (PMSPA) em feijão-caupi

\begin{tabular}{lccccc}
\hline & NVP & NSVG & AP & AF & PMSPA \\
\hline PROD & $0,977^{\mathrm{ns}}$ & $0,461^{\mathrm{ns}}$ & $-0,078^{\mathrm{ns}}$ & $1,039^{*}$ & $0,907^{\mathrm{ns}}$ \\
NVP & - & $0,317^{\mathrm{ns}}$ & $-0,003^{\mathrm{ns}}$ & $1,071^{*}$ & $0,828^{\mathrm{ns}}$ \\
NSVG & & - & $-0,887^{\mathrm{ns}}$ & $0,253^{\mathrm{ns}}$ & $0,942^{\mathrm{ns}}$ \\
AP & & - & $0,092^{\mathrm{ns}}$ & $-0,684^{\mathrm{ns}}$ \\
AF & & & - & - & $0,702^{\mathrm{ns}}$ \\
\hline
\end{tabular}

${ }^{*}$ Correlação significativo a 5\% pelo teste de Mantel, com 5000 simulações; ${ }^{\text {ns C} C o r r e l a c ̧ a ̃ o ~ n a ̃ o ~ s i g n i f i c a t i v a ; ~}{ }^{*}$ Estimativas de correlação genotípica superiores a 1,000 se devem ao método de estimação utilizado 
Dos componentes primários, destacou-se a relação genética entre o número de vagens planta $^{-1}(\mathrm{NVP})$ e a produtividade (PROD) que, além da alta correlação, exibiu elevado efeito direto e positivo $(r=0,924)$, superando em 6,65 vezes o efeito residual $(r=0,139)$ (Tabela 2).

Verificou-se também que o efeito indireto via o caráter NVP $(r=0,293)$ na relação entre número de sementes vagem ${ }^{-1}$ (NSVG) e produtividade, superou o efeito direto $(r=0,168)$. O número de vagens por planta está relacionado com a intensidade do dreno de fotoassimilados atuando negativamente sobre o peso do grão e a produtividade em plantas de feijão-caupi (SILVA; NEVES, 2011). Interpretações semelhantes sobre a relação linear de causa-efeito entre NVPxPROD são corroboradas por resultados apresentados por Cargnelutti Filho et al., (2011), Cabral et al., (2011), Dursun (2007), Furtado et al., (2002), Zilio et al., (2011) para feijão comum, e feijão-caupi (ANDRADE et al., 2010; SILVA; NEVES, 2011). O número de vagens por planta é um componente de produção cuja resposta correlacionada à produtividade mostra-se eficiente por meio da seleção indireta em feijão-caupi (SILVA; NEVES, 2011).

A variação dos caracteres NVP e NSVG representaram uma fração considerável da variabilidade atribuída ao caráter principal, expressa pelo valor de $\mathrm{R}^{2}=0,981$. A primeira cadeia do diagrama causal (Figura 1) mostrou ser eficiente em decompor as relações de causa e efeito dos componentes de produção dessa leguminosa.

Embora as correlações genotípicas entre a produtividade com a área foliar (AF) e com o peso da matéria seca da parte aérea (PMSPA) tenham sido estimativas positivas e elevadas, elas possuem naturezas distintas (Tabela 3 ).

O caráter AF apresentou efeito direto alto e positivo $(\mathrm{r}=1,685)$ sobre o caráter principal PROD, indicando ser este um caráter auxiliar na seleção de plantas, de tal modo que a resposta correlacionada por meio da seleção indireta será eficiente (CRUZ; REGAZZI; CARNEIRO,
Figura 1 - Diagrama ilustrativo representando, nas setas unidirecionais, os efeitos diretos dos componentes de produção (primários: número de vagens.planta-1 ${ }^{-1} \mathrm{NVP}$; número de sementes. vagem $^{-1}$ - NSVG) e caracteres agronômicos (secundários: altura da planta - AP; área foliar - AF; peso matéria seca da parte aérea - PMSPA) sobre o caráter principal, produtividade. As setas bidirecionais e pontilhadas representam os efeitos indiretos

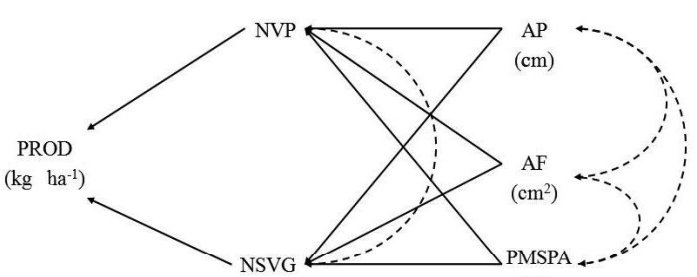

(g)

Primários Secundários

2004). A área foliar está relacionada ao tamanho das lâminas foliares ou à emissão de folhas em grande número. Plantas com grande área foliar possuem maior potencial fotossintético que pode proporcionar acúmulo de biomassa nos diferentes órgãos, principalmente naqueles de interesse econômico. Considerando que o incremento na área foliar sobre a área de plantio aumenta o peso da matéria seca da parte aérea $\left(\mathrm{r}_{\mathrm{AFxPMSPA}}=0,702\right.$, Tabela 1), acredita-se que esta relação possua um patamar ou valor ótimo, que ao ser ultrapassado caracteriza alto sombreamento, prejudicial ao crescimento das plantas.

O PMSPA mostrou efeito direto desfavorável sobre a produtividade $(\mathrm{r}=-0,818)$, ou seja, como caráter auxiliar não é o principal determinante das alterações na produtividade, o que foi constatado pelos efeitos indiretos via, principalmente AF e, AP (Tabela 3). Na partição de fotoassimilados há competição entre os órgãos drenos, prevalecendo aquele que apresentar maior nível de descarregamento e atividade metabólica. Esta distribuição pode ser alterada durante o enchimento dos grãos e as limitações no ganho de biomassa podem ocorrer em

Tabela 2 - Estimativas dos efeitos diretos e indiretos do número de vagens.planta ${ }^{-1}$ (NVP) e número de sementes.vagem ${ }^{-1}$ (NSVG) sobre a produtividade (PROD) em feijão-caupi

\begin{tabular}{lcccc}
\hline \multirow{2}{*}{ Caracteres } & \multirow{2}{*}{ Efeito Direto } & \multicolumn{2}{c}{ Efeito indireto } & \multirow{2}{*}{ Correlação $^{\text {s }}$} \\
\cline { 3 - 4 } NVP & 0,924 & NVP & NSVG & 0,977 \\
NSVG & 0,168 & 0,293 & 0,053 & 0,461 \\
$\mathrm{R}^{2 *}$ & 0,981 & & - & \\
Efeito residual & 0,139 & & & \\
\hline
\end{tabular}

${ }^{\#} \mathrm{R}^{2}$ : Coeficiente de determinação; ${ }^{\mathrm{s} E s t i m a t i v a s ~ d e ~ c o r r e l a c ̧ a ̃ o ~ g e n o t i ́ p i c a ~ e n t r e ~ o s ~ r e s p e c t i v o s ~ c o m p o n e n t e s ~ d e ~ p r o d u c ̧ a ̃ o ~ e ~ a ~ p r o d u t i v i d a d e ~}$ 
Tabela 3 - Estimativas dos efeitos diretos e indiretos dos componentes secundários, altura da planta (AP), área foliar (AF) e peso da matéria seca da parte aérea (PMSPA) sobre a produtividade (PROD) em feijão-caupi

\begin{tabular}{lccccc}
\hline \multirow{2}{*}{ Características } & Efeito Direto & \multicolumn{3}{c}{ Efeito Indireto } & Correlação $^{\$}$ \\
\cline { 3 - 6 } & & AP & AF & PMSPA & $-0,078$ \\
\hline AP & $-0,792$ & - & 0,155 & 0,559 & 1,039 \\
AF & 1,685 & $-0,073$ & - & $-0,574$ & 0,907 \\
PMSPA & $-0,818$ & 0,542 & 1,183 & - & \\
R & 1,071 & & & & \\
Efeito residual & 0,000 & & & & \\
\hline
\end{tabular}

${ }^{\text {}} \mathrm{R}^{2}$ : Coeficiente de determinação. ${ }^{\$}$ Estimativas de correlação genotípica entre componentes secundários e produtividade. Estimativas com magnitudes maiores que 1 se devem ao método de estimação utilizado

algum momento do desenvolvimento da planta. A maioria das cultivares avaliadas - BR8 Caldeirão, BRS Guariba e BR17 Gurguéia - apresentam hábito de crescimento indeterminado nas quais a fase de crescimento vegetativo não é interrompida com a emissão dos botões florais, o que resulta em menor disponibilidade de fotoassimilados para os grãos, mas com maior duração da área foliar e maior produtividade (FREIRE FILHO et al., 2007; OLIVEIRA et al., 2010; SILVA; NEVES, 2011). O surgimento de tecidos e estruturas não assimilatórias, além da senescência e queda de folhas, também podem afetar negativamente a produção (FALQUETO et al., 2009).

Apesar da altura da planta ter baixo efeito direto sobre a produtividade, cabe considerar que este caráter não deve ser totalmente descartado de seleções indiretas, pois a seleção simultânea poderá proporcionar resultados satisfatórios. A cadeia secundária no diagrama de trilha mostrou ser eficiente em decompor as correlações entre caracteres agronômicos e produtividade de grãos $\left(\mathrm{R}^{2}=\right.$ 1.071 e efeito residual nulo).

Na Tabela 4 encontra-se a decomposição das associações genotípicas em efeitos diretos e indiretos entre componentes primários e secundários.

Os caracteres secundários AF, AP e PMSPA foram suficientes para explicar as variações no número de vagens $\left(\mathrm{R}^{2}=1,157\right.$ e efeito residual nulo), com destaque para o efeito direto da área foliar $(\mathrm{r}=1,083)$.

Tabela 4 - Estimativas dos efeitos diretos e indiretos dos caracteres secundárias altura da planta (AP), área foliar (AF) e peso da matéria seca da parte aérea (PMSPA) sobre os caracteres primários número de vagens por planta (NVP) e número de sementes por vagens (NSVG) em feijão-caupi

\begin{tabular}{lccccc}
\hline \multirow{2}{*}{ Caracteres } & Efeito Direto & \multicolumn{3}{c}{ Efeito indireto } & Correlação $^{\$}$ \\
\cline { 3 - 5 } & & AP & AF & PMSPA \\
\hline AP & $-0,105$ & - & 0,099 & 0,003 & $-0,003$ \\
AF & 1,083 & $-0,010$ & - & $-0,003$ & 1,071 \\
PMSPA & $-0,004$ & 0,072 & 0,760 & - & 0,828 \\
$\mathrm{R}^{2 \#}$ & 1,157 & & & & \\
Efeito residual & 0,000 & & & 0,919 & $-0,887$ \\
\hline & & Número de sementes por vagem & $-0,943$ & 0,253 \\
\hline AP & $-1,932$ & - & 0,126 & - \\
AF & 1,374 & $-0,177$ & - & 0,942 \\
PMSPA & $-1,344$ & 1,322 & 0,964 & \\
$\mathrm{R}^{2 \#}$ & 0,797 & & & \\
Efeito residual & 0,451 & & & \\
\hline
\end{tabular}

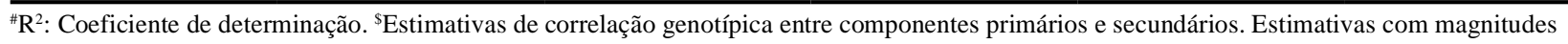
maiores que 1 se devem ao método de estimação utilizado 
A área foliar é um componente secundário que deve ser utilizado como fator de seleção para componentes primários - número de vagens e número de sementes e produtividade de grãos - em razão de seus efeitos diretos e indiretos elevados e em sentido favorável à seleção.

Embora todos os efeitos diretos dos caracteres secundários (AP, AF e PMSPA) com o número de sementes sejam consideravelmente superiores à magnitude do efeito residual $(\mathrm{r}=0,451)$, os mesmos não explicaram tão bem a variação do caráter NSVG quando comparado ao componente primário $\mathrm{NVG}$, cujo efeito residual foi nulo (Tabela 4). Em investigações futuras seria interessante inserir novos caracteres, na tentativa de melhor elucidar as relações de causa-efeito com NSVG. De todo modo, estes componentes secundários não devem ser descartados, pois apresentaram efeitos diretos e indiretos elevados.

\section{CONCLUSÕES}

1.O diagrama de trilha com duas cadeias mostra-se adequado em explicar as relações entre componentes primários, secundários e produtividade, considerando as altas estimativas dos coeficientes de determinação $\left(\mathrm{R}^{2}\right)$ e baixos efeitos residuais;

2.O número de vagens planta ${ }^{-1}$ e a área foliar são os caracteres mais correlacionados com a produtividade e se mostram eficientes em praticar-se seleção indireta, com o intuito de obter ganhos genéticos sob o rendimento de grãos. Também mostram ser caracteres importantes sob os efeitos indiretos do número de sementes vagem ${ }^{-1}$, altura da planta e peso da matéria seca da parte aérea.

\section{REFERÊNCIAS}

ANDRADE, F. A. et al. Estimativas de parâmetros genéticos em genótipos de feijão-caupi avaliados para feijão fresco. Revista Ciência Agronômica, v. 41, n. 2, p. 253-258, 2010.

BEZERRA, A. A. C. et al. Características de dossel e de rendimento em feijão-caupi ereto em diferentes densidades populacionais. Pesquisa Agropecuária Brasileira, v. 44, n. 10, p. 1239-1245, 2009.

BEZERRA, A. A. C. et al. Inter-relação entre caracteres de caupi de porte ereto e crescimento determinado. Pesquisa Agropecuária Brasileira, v. 36, n. 3, p. 137-142, 2001.

CABRAL, P. D. S. et al. Análise de trilha do rendimento de grãos de feijoeiro (Phaseolus vulgaris L.) e seus componentes. Revista Ciência Agronômica, v. 42, n. 1, p. 132-138, 2011.
CARGNELUTTI FILHO, A. et al. Número necessário de experimentos para a análise de trilha em feijão. Ciência Rural, v. 41, n. 4 , p. 564-572, 2011.

COIMBRA, J. L. M. et al. Análise de trilha I: análise do rendimento de grãos e seus componentes. Ciência Rural, v. 29, n. 2, p. 213-218, 1999.

CRUZ, C. D. Programa Genes: estatística experimental e matrizes. Viçosa: Editora UFV, 2006. 285 p.

CRUZ, C. D.; REGAZZI, A. J.; CARNEIRO, P. C. S. Modelos biométricos aplicados ao melhoramento genético. 3. ed. Viçosa: Editora UFV, 2004. 480 p. v. 1.

DURSUN, A. Variability, heritability and correlation studies in bean (Phaseolus vulgaris L.) genotypes. Word Journal of Agricultural Sciences, v. 3, n. 1, p. 12-16, 2007.

FALQUETO, A. R. et al. Crescimento e partição de assimilados em cultivares de arroz diferindo no potencial de produtividade de grãos. Bragantia, v. 68, n. 3, p. 563-571, 2009.

FERREIRA, F. M. et al. Relações fenotípicas e genotípicas entre componentes de produção em cana-de-açúcar. Bragantia, v. 66 , n. 4, p. 605-610, 2007.

FREIRE FILHO, F. R. et al. Melhoramento genético. In: FREIRE FILHO, F. R.; LIMA, J. A. A.; RIBEIRO, V. Q. Feijãocaupi: avanços tecnológicos. Brasília: Embrapa Informação Tecnológica, 2005. cap. 1, p. 29-75.

FREIRE FILHO, F. R. et al. Novo gene produzindo cotilédone verde em feijão-caupi. Revista Ciência Agronômica, v. 38, n. 3, p. 286-290, 2007.

FURTADO, M. R. et al. Análise de trilha do rendimento do feijoeiro e seus componentes primários em monocultivo e em consórcio com a cultura do milho. Ciência Rural, v. 32, n. 2, p. 217-220, 2002.

KRAUSE, W.; RODRIGUES, R.; LEAL, N. R. Capacidade combinatória para características agronômicas em feijão-devagem. Revista Ciência Agronômica, v. 43, n. 3, p. 522531, 2012.

MONTGOMERY, D. C.; PECK, E. A. Introduction to linear regression analysis. New York: John Wiley \& Sons, 1981. 504 p.

OLIVEIRA, O. M. S. et al. Período de convivência das plantas daninhas com cultivares de feijão-caupi em várzea no Amazonas. Planta daninha, v. 28, n. 3, p. 523-530, 2010.

RAMALHO, M. A. P.; SANTOS, J. P.; ZIMMERMANN, M. J. Genética quantitativa em plantas autógamas: aplicações ao melhoramento do feijoeiro. Goiânia: Editora UFG, 1993. $271 \mathrm{p}$.

ROCHA, M. M. et al. Controle genético do comprimento do pedúnculo em feijão-caupi. Pesquisa Agropecuária Brasileira, v. 44, n. 3, p. 270-275, 2009.

SILVA, J. A. L.; NEVES, J. A. Componentes de produção e suas correlações em genótipos de feijão-caupi em cultivo de sequeiro e irrigado. Revista Ciência Agronômica, v. 42, n. 3, p. $702-713,2011$. 
SOUZA, C. L. C. Variabilidade, correlações e análise de trilha em Populações de feijão-caupi (Vigna unguiculata (l.) Walp.) para produção de grãos verdes. 2005. $58 \mathrm{f}$. Dissertação (Mestrado em Genética e Melhoramento) Universidade Federal do Piauí, Terezina, 2005.
VIANELlO, R. L.; ALVES, A. R. Meteorologia básica e aplicações. Viçosa: Editora UFV, 2002. 448 p.

ZILIO, M. et al. Contribuição dos componentes de rendimento na produtividade de genótipos crioulos de feijão (Phaseolus vulgaris L.). Revista Ciência Agronômica, v. 42, n. 2, p. 429-438, 2011. 